\title{
Olea europaea L. Polenlerinin Aydın, Manisa ve Muğla Atmosferindeki Dă̆ılımları
}

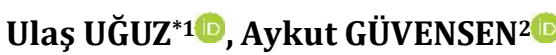

\author{
1,2Ege Üniversitesi, Fen Fakültesi, Biyoloji Bölümü, 35040, İzmir, Türkiye
}

(Alınış / Received: 14.05.2019, Kabul / Accepted: 11.10.2019, Online Yayınlanma / Published Online: 30.12.2019)

Anahtar Kelimeler
Zeytin,
Atmosferik parametreler,
Polen
Özet: Bu çalışmada zeytin ağaçlarının geniş yayllış gösterdiği Aydın, Manisa ve Muğla atmosferlerindeki Olea europaea L. polenlerinin dağılımları incelenmiştir. Volumetrik yöntem ile 2014-2016 yılları arasında gerçekleştirilen çalışmada bu taksona ait polenlerin ylllık değişimleri ve polen sezonu üzerinde meteorolojik faktörlerin etkisi incelendi. İki ylllı çalışma süresince zeytin polenlerine en fazla rastlanan ilin Aydın olduğu görüldü. Bu şehirde zeytin polenlerinin atmosferde kaydedilen tüm polenlerin \%20.92'sini oluşturduğu ve baskın taksonlar içerisinde ilk sırada yer aldığı belirlendi. Bununla beraber, zeytin polenleri Manisa ve Muğla'da sırasıyla \%15.55 ve \%7.16 ile üçüncü sırada yer aldı. Bu bitkinin polenleri tüm bölgelerde en fazla Mayıs ayında kaydedildi, ancak esas polen dönemlerinin çalışılan iller ve yıllar arasındaki meteorolojik değişimlerin etkisiyle farklılıklar gösterdiği görüldü. Diğer taraftan bu taksona ait günlük polen sayıları, meteorolojik faktörlerle korale edildi ve günlük ortalama sıcaklık $\left({ }^{\circ} \mathrm{C}\right)$, günlük toplam yağış $(\mathrm{mm})$ ve günlük ortalama nisbi nem (\%) ile günlük polen saylları arasında Spearman korelasyon testine göre anlamlı sonuçlar bulundu $(\mathrm{p}<0.01$, $\mathrm{p}<0.05)$.

\section{The Distribution of Olea europaea L. Pollen in the Atmospheres of Aydın, Manisa and Muğla}

\section{Keywords}

Olive,

Atmospheric parameters, Pollen

\begin{abstract}
In this study, the distribution of Olea europaea L. pollens in the atmospheres of Aydın, Manisa and Muğla, where the olive trees are widespreated were investigated. Accordance with the volumetric method, the annual changes of pollen from this taxon and the effect of meteorological factors on the pollen season were investigated between 2014-2016. Aydin is the province with the highest number of olive pollen in the atmosphere during two years study period. Olive pollen in this city accounted for $20.92 \%$ of all pollens recorded in the atmosphere and ranked first among the dominant taxa. However in Manisa and Muğla olive pollen ranked third with $15.55 \%$ and $7.16 \%$ respectively. Highest olive pollen counts were dedected in May in all regions but it was observed that the main pollen seasons differed by the effects of meteorological changes between the provinces and the years. On the other hand daily pollen counts belonging to this taxon were correlated with the meteorological parameters and significant results were determined between daily pollen count and daily average temperature $\left({ }^{\circ} \mathrm{C}\right)$, total precipitation $(\mathrm{mm})$ and daily average relative humidity (\%) according to the Spearman correlation test $(\mathrm{p}<0.01, \mathrm{p}<0.05)$.
\end{abstract}

\section{Giriş}

Havada bulunan ve solunum yoluyla alerjik semptomlara neden olan aeroallerjenlerin başında polenler gelmektedir. Rüzgar ile tozlaşan bitkilerin polenleri atmosferde uzun mesafeler taşınabilir ve disseminasyon sezonunun süreci iklim ve vejetasyona bağlı olarak yöresel farklılıklar göstermektedir [1]. Bu nedenle farklı bölgelere ait atmosferik polen verileri klinisyenler ve alerji hastalarının saman nezlesi semptomlarını çok daha iyi yönetebilmeleri açısından önem taşımaktadır [2]. Bununla beraber atmosferdeki polen konsantrasyonunun meteorolojik değişimlerden büyük ölçüde etkilendiği bilinmektedir $[3,4]$ ve tüm dünyada olduğu gibi Türkiye'nin de farklı bölgelerinde değişik yöntemler kullanılarak yapılan çok sayıdaki aeropalinolojik çalışmada, atmosferik 
polenlerin tespit edilmesi ve meteorolojik faktörlerle ilişkileri açısından önemli veriler elde edilmiștir [510]. Aeropalinolojik çalışmalarda tanımlanan polenler genellikle ağaç, çayır ve yabani otsular olmak üzere üç grupta incelenmektedir. Ağaç polenleri içerisinde yer alan Olea europaea L. polenleri de önemli aeroallerjenlerden biri olarak gösterilmektedir [11].

Zeytin ağacı (Olea europaea) Akdeniz havzasında ekimi çok eski çağlara dayanan ve bu bölgedeki insanlar için ekonomik, sosyal ve kültürel anlamda oldukça önemli bir bitkidir [12]. Genellikle Akdeniz ikliminin hüküm sürdüğü yerlerde yayılış gösteren bu ağacın, ülkemizde iki varyetesi bulunmaktadır (var. europaea Zhukovsky ve var. sylvestris (Miller) Lehr.) [13]. Her iki varyete de Kuzey, Batı ve Güney Anadolu'da yayılış göstermektedir. Bunlardan Olea europaea var. europaea' nın zeytinyağı üretimi için geniş çaplı kültürü yapılmaktadır [14]. Türkiye dünyanın en iyi beş zeytinyağı üreticisinden biridir ve son on yıl içerisinde zeytin ağaçlarının sayısı \%60, dikili alanların oranı \%25 oranında artmıştır [15]. Türkiye'de zeytin üretimi açısından önemli bölgelerin başında Ege bölgesi gelmekte ve bunu Akdeniz ve Marmara bölgeleri takip etmektedir [16].

Olea europaea anemofil (rüzgarla tozlaşan ) bir bitkidir [17] ve bu bitkinin polenleri, Akdeniz ülkelerinde hastalar ve doktorlar açısından önemli alerjik problemlere yol açmaktadır [18,19]. Bu ülkelerde yapılan bazı çalışmalarda bitkiye ait polenlerin alerjik reaksiyonlarda artışa sebep olduğu ve deri prick testlerinde polinosis hastalarının bu polenlere karșı duyarlılık gösterdiği saptanmıștır [1, $2,20]$. Ülkemizde yapılan aeropalinolojik çalışmalarda özellikle Akdeniz ikliminin etkisindeki bölgelerde bu taksona ait polenler havada yüksek oranlarda tespit edilmiştir [21-24].

$\mathrm{Bu}$ çalışmada Ege Bölgesi ve Türkiye'nin zeytin ağaçlarının kapladığı alan bakımından ilk üç sırada yer alan Aydın, Manisa ve Muğla illerinde Olea europaea polenlerinin atmosferdeki dağılımının ortaya konması ve bu taksona ait atmosferdeki polen miktarının meteorolojik faktörlerle olan ilişkilerinin istatistiksel veriler ışığında değerlendirilmesi amaçlandı.

\section{Materyal ve Metot}

Çalışma kapsamında Manisa, Muğla ve Aydın illerinde 1 Şubat 2014- 1 Şubat 2016 tarihleri arasında 2 yıl süre ile atmosferik polen çalışmaları gerçekleştirildi (Şekil 1). Volumetrik yöntem ile gerçekleştirilen çalışmada Lanzoni VPPS 2010 model polen yakalama cihazları kullanıldı. Polen yakalama cihazları her şehirde etrafı hava akımlarına açık olan, yaklaşık 25 m yükseklikte, kesintisiz enerji kaynağına sahip ve şehri temsil eden noktalara yerleştirildi. Polen yakalama cihazları üzerinde bulunan ve tam devrini 1 haftada tamamlayan disk haftalık olarak değiștirildi.
Disk üzerinden alınan bantlar laboratuvara getirildi ve 7 eşit parçaya ayrılarak, her biri 1 günü temsil eden preparatlar hazırlandı. Polenlerin teşhis ve sayım işlemlerinde Olympus marka ışık mikroskobu ve $400 \mathrm{X}$ büyütme kullanıldı. Her bir preparattaki 48 mm boyundaki melineks bantın tamamı, tüm lamel alanı yukarıdan aşağıya doğru taranacak şekilde incelendi ve 1 güne karşllı gelen polen konsantrasyonları ortaya konuldu.

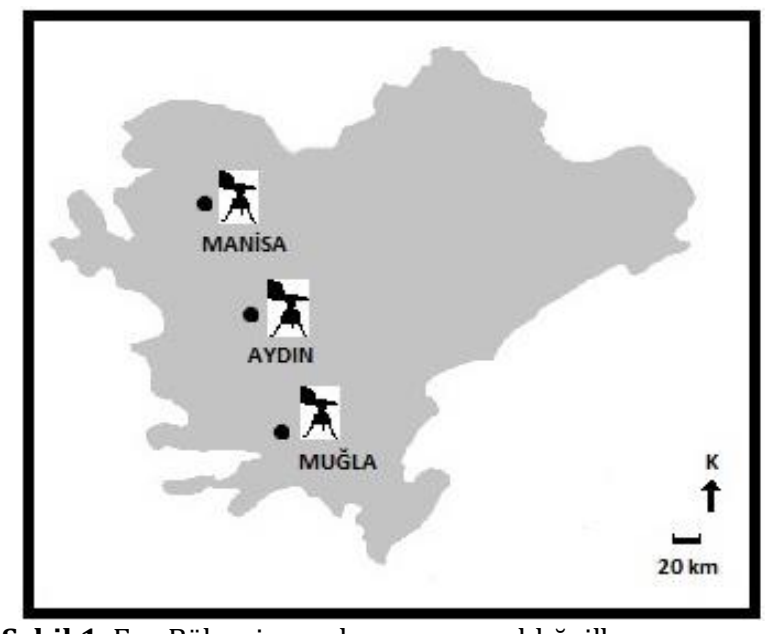

Şekil 1. Ege Bölgesi ve çalışmanın yapıldığı iller.

Atmosferik örnekleme ve sayım işlemleri Spanish Aerobiological Network (REA) tarafindan tanımlanan metod ile yapılmış [25] ve 1 güne karşılık gelen polen konsantrasyonları belirlendi. Yıl içerisindeki esas polen döneminin (MPS) belirlenmesinde \%95 metodu kullanıldı [26]. Buna göre esas polen döneminin başladığı gün 1 Şubat tarihi esas alınarak, yıllık toplam polen sayısının (annual pollen index, API) \%2.5'e ulaştığ gün olup, bitiş tarihi ise \%97.5'e ulaştığı gün olarak hesaplandı. Çalışılan şehirlere ait meteorolojik veriler Türkiye Meteorolojik Veri Arşiv Sistemi (TÜMAS)'ne aktarılan veriler üzerinden alındı. Çalışma dönemine ait saatlik ortalama sıcaklık $\left({ }^{\circ} \mathrm{C}\right)$, saatlik nisbi ortalama nem (\%), günlük toplam yağıș (mm) ve saatlik ortalama rüzgar hızı (m s${ }^{-1}$ ) verileri sistem üzerinden kaydedildi. İstatistiksel analizlerde Olea europaea esas polen dönemlerine (main pollen season, MPS) ait günlük ortalama polen sayıları ile aynı günlere ait ortalama sıcaklık $\left({ }^{\circ} \mathrm{C}\right)$, ortalama nisbi nem (\%), toplam yağıș (mm) ve ortalama rüzgar hızı (m s $\left.\mathrm{s}^{-} 1\right)$ parametreleri korale edildi. İstatistiksel değerlendirmeler Spearman Korelasyon Testi ile SPSS 20 programı kullanılarak yapılmıştır.

\section{Bulgular}

Araştırmanın gerçekleştiği 2 yıllık süreçte Manisa ilinde 46 taksona ait toplam 17.201 polen $/ \mathrm{m}^{3}$ adet polen tespit edildi. $\mathrm{Bu}$ taksonlar içerisinde Olea europaea, Quercus spp. ve Pinaceae' nin ardından polenlerine en fazla rastlanan üçüncü taksondur ve atmosferdeki toplam polen miktarının \%15.55'ini oluşturmaktadır. Çalışmanın ilk yılında Manisa atmosferinde $O$. europaea polen miktarı 1743 
polen $/ \mathrm{m}^{3}$ adet kaydedildi ve polenlerine en fazla rastlanan takson olduğu saptandı. $\mathrm{Bu}$ yll atmosferdeki toplam polenlerin \%21.57'sini olușturmaktadır. İkinci yll ise 932 polen $/ \mathrm{m}^{3}$ adet ve $\% 10.22$ ile polenlerine en fazla rastlanan dördüncü takson olarak belirlendi.

Çalışmanın ilk yılı Manisa atmosferinde 0 . europaea polenleri Nisan-Ağustos ayları arasında gözlemlendi ve en yüksek miktarı Mayıs ayında kaydedildi. İkinci yıl ise Mayıs-Eylül aylarında polenlerine rastlandı ve en yüksek miktarına yine Mayıs ayında kaydedildi. İlk yll polen mevsimi 21 Nisan 2014-30 Ağustos 2014 tarihleri arasında gerçekleșmiş ve atmosferde 75 gün polenlerine rastlandı. En yüksek polen sayısı 19 Mayıs günü kaydedildi. İkinci yıl ise 02 Mayıs 201528 Eylül 2015 tarihleri arasında 88 gün polenlerine rastlandı ve en yüksek polen sayısı 16 Mayıs günü kaydedildi. Manisa atmosferinde O. europaea esas polen dönemi her iki yılda da 24 gün sürmüş ve ilk yıl 02 Mayıs- 25 Mayıs tarihlerinde, ikinci yll ise 14 Mayıs- 6 Haziran tarihleri arasında kaydedildi (Şekil 2).

Aydın ilinde iki yıllık çalışma süresince 46 taksona ait toplam 38451 polen $/ \mathrm{m}^{3}$ adet polen tespit edildi. Bu polenlerin içerisinde 0 . europaea iki ylllı ortalama değerlere göre polenlerine en fazla rastlanan taksondur (\%21.02). O. europaea polenleri toplam polen miktarının ilk yıl \%26.04'ünü (5046 polen $/ \mathrm{m}^{3}$ ), ikinci yll ise \%15.92'sini (3036 polen $\left./ \mathrm{m}^{3}\right)$ oluşturmaktadır. Zeytin polenleri ilk yll 4 Nisan 2014- 31 Ağustos 2014 tarihleri arasında 108 gün görüldü ve esas polen dönemi 30 Nisan- 1 Haziran arasında 32 gün sürmüștür. İkinci yll 25 Nisan 201531 Temmuz 2015 tarihleri arasında ve Eylül ayının 3 günü olmak üzere toplam 89 gün polenlerine rastlanmış ve esas polen dönemi 7 Mayıs- 4 Haziran tarihleri arasında 28 gün sürmüştür. Aydın atmosferinde bu taksona ait toplam polen miktarı ilk yll 06 Mayıs'ta, ikinci yıl ise 20 Mayıs'ta kaydedildi (Şekil 2).

Muğla atmosferinde iki ylllık sürecin sonunda 48 taksona ait toplam 35517 polen $/ \mathrm{m}^{3}$ adet polen tespit edildi. $\mathrm{Bu}$ süreçte ortalama değerlere göre $O$. europaea, Pinaceae ve Quercus'un ardından atmosferde polenlerine en fazla rastlanan takson olup ve tüm polenlerin \%7.16'sını oluşturmaktadır. İlk yıl kaydedilen tüm taksonlar içerisinde \% 6.11 (1251 polen $/ \mathrm{m}^{3}$ ) ile üçüncü sırada, ikinci yıl ise \% 8.59 (1291 polen $/ \mathrm{m}^{3}$ ) ile dördüncü sırada yer almıștır. $O$. europaea'nın polenleri birinci yll 07 Nisan 2014 - 30 Temmuz 2014 tarihleri arasında toplam 110 gün kaydedildi ve 26 Nisan günü 108 polen $/ \mathrm{m}^{3}$ adet ile en fazla polenin görüldügü gün olmuştur. İkinci yllda bu taksona ait polenler 04 Mayıs 2015 - 30 Temmuz 2015 tarihleri arasında toplam 55 gün gözlemlendi ve 24 Mayıs günü 154 polen $/ \mathrm{m}^{3}$ adet ile en fazla polenin görüldüğü gün olmuştur. 0 . europaea için esas polen sezonu ilk yll 22 Nisan - 29 Mayıs tarihleri arasında 38 gün, ikinci yıl ise 08 Mayıs - 05 Haziran tarihleri arasında 29 gün sürmüştür. Muğla atmosferinde her iki yılda da zeytin polenlerinin en fazla tespit edildiği ay Mayıs'tır (Şekil 2).

\section{Tartışma ve Sonuç}

Günümüze kadar Ege Bölgesi'ndeki il merkezleri ve özellikle kıyı bölgelerdeki bazı ilçelerde farklı araștırıcılar tarafından gerek gravimetrik, gerekse volumetrik yöntemle aeropalinolojik çalışmalar gerçekleştirilmiştir. Bu çalışmalarda özellikle Akdeniz ikliminin etkisi altındaki kıyı kesimlerde 0 . europaea polenlerinin atmosferdeki varlı̆̆ bölgedeki vejetasyona bağlı olarak oransal değişiklikler gösterse de, çoğunlukla polenlerine en fazla rastlanan taksonlar içerisinde üst sıralarda yer almıştır. Çalışmamızda Aydın ilinde polenlerine en fazla rastlanan takson iken, Muğla ve Manisa illerinde Pinaceae ve Quercus'un ardından polenleri en fazla kaydedilen üçüncü takson olduğu görüldü. Aydın ilinde $O$. europaea polen miktarının diğer iki ile oranla daha yüksek olması bölgedeki zeytin ağacı miktarı ile ilişkilendirilebilir. 2015 verilerine göre Aydın ilinde zeytin ağaçlarının kapladığı alan 154465 hektar iken, Manisa'da 97830, Muğla'da ise 94432 hektardır. Bölgedeki benzer çalışmaların bazılarında O. europaea, Denizli'de \%11.35 ile en fazla polenlerine rastlanan üçüncü takson [22], Gemlik'te \%18.19 ile ikinci takson [21], Kuşadası'nda \%34.46 ile en yüksek polen sayısına sahip takson [23] ve Çeşme'de \%12.51 ile polenleri en fazla kaydedilen ikinci takson [24] olmuştur.

Çalıştığımız bölgelerde zeytin polenlerinin genellikle sıcakların artmaya başladığı Nisan ve Mayıs aylarında görülmeye başlandığı ve Temmuz-Ağustos aylarına kadar atmosferde izlenebildiği kaydedilmiştir. $\mathrm{Bu}$ bölgelerde zeytin polenlerinin havada görülmeye başladığı günler çalışılan istasyonlar arasında ve yıllara göre farklılıklar göstermiştir. Manisa ilinde ilk yll 21 Nisan'da görülmeye başlayan zeytin polenleri, ikinci yıl ilk kez 2 Mayıs günü kaydedildi. Aydın'da ilk yıl 4 Nisan günü görülen polenler, ikinci yll 25 Nisan'da, Muğla'da ise ilk yıl 7 Nisan'da görülmeye başlayan zeytin polenleri, ikinci yıl 4 Mayıs günü kaydedilmeye başlanmıştır. Yıllar arasında ve çalıșma istasyonları arasında görülen bu farklılık büyük ölçüde bölgelerdeki meteorolojik faktörlerin farklılığından kaynaklanmaktadır.

Sıcaklık değişimlerinin O. europaea'nın fenolojisi ve çiçeklenme tarihleri üzerinde önemli etkisi vardır [27]. Manisa'da ilk yıl Nisan ayında ortalama sıcaklık $16.42^{\circ} \mathrm{C}$ iken, ikinci yll bu değer $13.86^{\circ} \mathrm{C}$ ölçülmüştür. Bununla beraber günlük sıcaklık ortalamalarına baktığımızda ilk yıl Nisan ayının sonlarına doğru sıcaklıkların arttığı ve birkaç gün $20^{\circ} \mathrm{C}$ 'nin üzerinde ölçüldüğü görülmektedir. İkinci yılın Nisan ayında sıcaklıkların ilk yıla oranla daha düşük seyrettiği ve sıcaklıkların yükselişinin Mayıs ayı başlarında olduğu kaydedildi. Benzer şekilde Aydın ilinde ilk yılın Nisan ayında ortalama sıcaklık $18.27^{\circ} \mathrm{C}$ iken ikinci yıl $17^{\circ} \mathrm{C}$ 
ölçülmüştür. Günlük değerler incelendiğinde ilk yıl kısa süreli görülen yağışlara karşın ortalama sıcaklıklar ikinci yıla oranla daha yüksek seyretmiștir. Bununla beraber ikinci yıl Nisan ayının ilk yarısı daha fazla yağışlı gün kaydedildi ve ortalama sıcaklıkların özellikle ayın son günlerinde artışa geçtiği görülmektedir. Muğla'da Nisan ayı ortalama sıcaklığı ilk yll $13.07^{\circ} \mathrm{C}$ ölçülürken, ikinci yıl $11.94^{\circ} \mathrm{C}$ ölçülmüş ve bu yıl günlük sıcaklık ortalamaları Mayıs ayından itibaren artış göstermiştir. Tüm istasyonlarda polen sezonu içerisinde görülen kısa süreli yağışlar, yıkanma etkisinden dolayı atmosferdeki polen miktarlarında kısa süreli düşüşlere neden olmuştur (Tablo 1). Malaga (İspanya) atmosferinde yapllan bir çalışmada elde edilen benzer sonuçlarda 0 . europaea polen dağılımı üzerinde sıcaklık ve güneşlenme süresinin pozitif etkisi olduğu ve polen sezonu içerisindeki kısa süreli yağıșların anlık yıkanma etkisi gösterdiği rapor edilmiştir [28].

Meteorolojik faktörlerin etkisi çalıșma bölgelerindeki zeytin polenlerinin atmosferde görülmeye başladığı tarih ve dağılımı kadar, esas polen dönemi üzerinde de etkili olmuştur. Her üç çalışma bölgesinde de $O$. europaea esas polen döneminin başlangıcl Nisan sonu- Mayıs başında gerçekleşmektedir. Bununla beraber ilk yll esas polen döneminin ikinci yıla oranla daha erken başladığı kaydedildi. Polinasyon döneminin başladığı Nisan ayının sıcaklık ortalamaları incelendiğinde tüm illerde ilk yll kaydedilen ortalama sıcaklıkların ikinci yla oranla daha yüksek olduğu tespit edildi.

Çalışma süresince meteorolojik faktörlerin zeytin polenlerinin atmosferdeki dağılımı üzerindeki etkileri istatistiksel olarak incelendi. Elde edilen sonuçlara göre ortalama sicaklık ile toplam polen sayısı arasındaki ilişki Aydın ve Muğla illerindeki ikinci çalışma yılında anlamlı bulundu. Bununla birlikte ikinci yıl ortalama nem ile toplam polen sayısı arasında her üç ilde de negatif ilişki kaydedildi. Toplam yağışın negatif etkisi ise Muğla ilinde ikinci yıl yapılan çalışma için anlamlı bulunmuştur. Ortalama rüzgar hızı ile toplam polen sayısı arasında anlamlı bir ilişki her üç İl'de de kaydedilmemiştir (Tablo 2).
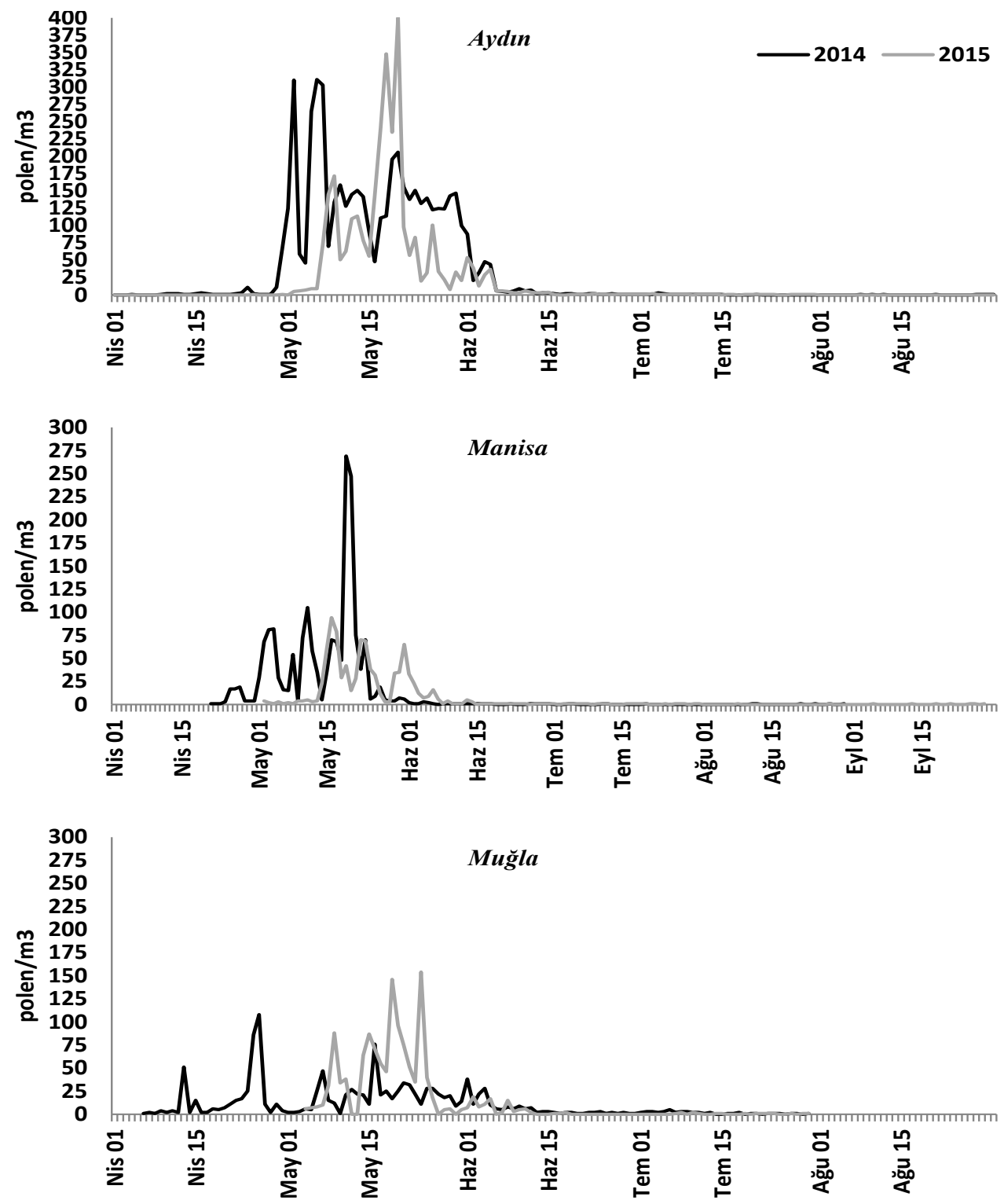

Șekil 2. Aydın, Manisa ve Muğla atmosferindeki polenlerin günlük dağılımı. 
Tablo 1. Meteorolojik parametrelerin aylık ortalama değerleri.

\begin{tabular}{|c|c|c|c|c|c|c|}
\hline \multicolumn{7}{|c|}{ Sicaklık $\left({ }^{\circ} \mathrm{C}\right)$} \\
\hline & \multicolumn{2}{|c|}{ Manisa } & \multicolumn{2}{|c|}{ Muğla } & \multicolumn{2}{|c|}{ Aydın } \\
\hline & 2014 & 2015 & 2014 & 2015 & 2014 & 2015 \\
\hline Mart & 12.27 & 10.82 & 10.1 & 9.05 & 14.34 & 13.3 \\
\hline Nisan & 16.42 & 13.86 & 13.07 & 11.94 & 18.27 & 17 \\
\hline Mayıs & 20.62 & 21.66 & 17.83 & 19.81 & 23,03 & 24 \\
\hline Haziran & 24.26 & 23.78 & 22.46 & 21.75 & 27.73 & 26.3 \\
\hline Temmuz & 29.48 & 29.1 & 26.2 & 28.5 & 30.22 & 32 \\
\hline Ağustos & 29.58 & 28.66 & 29.34 & 26.62 & 31.25 & 29.07 \\
\hline \multicolumn{7}{|c|}{ Yağıș (mm) } \\
\hline & \multicolumn{2}{|c|}{ Manisa } & \multicolumn{2}{|c|}{ Muğla } & \multicolumn{2}{|c|}{ Aydın } \\
\hline & 2014 & 2015 & 2014 & 2015 & 2014 & 2015 \\
\hline Mart & 3.21 & 2.41 & 6.7 & 6.35 & 2.06 & 3.3 \\
\hline Nisan & 5.44 & 1.08 & 2.28 & 0.84 & 2.54 & 0.94 \\
\hline Mayıs & 1.08 & 1.74 & 3.08 & 2.87 & 0.48 & 3.2 \\
\hline Haziran & 1.96 & 1.83 & 1.52 & 1.96 & 1.72 & 0.29 \\
\hline Temmuz & 0.26 & 0.01 & 1.87 & 0.78 & 0 & 0.1 \\
\hline Ağustos & 0.49 & 2.4 & 0.24 & 1.6 & 0 & 0 \\
\hline \multicolumn{7}{|c|}{ Nem (\%) } \\
\hline & \multicolumn{2}{|c|}{ Manisa } & \multicolumn{2}{|c|}{ Muğla } & \multicolumn{2}{|c|}{ Aydın } \\
\hline & 2014 & 2015 & 2014 & 2015 & 2014 & 2015 \\
\hline Mart & 64.19 & 72.38 & 70.07 & 76.54 & 58.29 & 67 \\
\hline Nisan & 61.23 & 56.95 & 70.58 & 58.85 & 55.03 & 50.1 \\
\hline Mayıs & 56.24 & 51.63 & 66.2 & 57.17 & 49.50 & 54 \\
\hline Haziran & 54.49 & 58.34 & 55.08 & 58.11 & 42.94 & 51.8 \\
\hline Temmuz & 41.69 & 42.39 & 47.28 & 41.9 & 41.83 & 42.21 \\
\hline A ğustos & 45.79 & 48.94 & 41.19 & 46.61 & 42.72 & 53.1 \\
\hline \multicolumn{7}{|c|}{ Rüzgar Hızı (m s¹) } \\
\hline & \multicolumn{2}{|c|}{ Manisa } & \multicolumn{2}{|c|}{ Muğla } & \multicolumn{2}{|c|}{ Aydın } \\
\hline & 2014 & 2015 & 2014 & 2015 & 2014 & 2015 \\
\hline Mart & 0.62 & 0.51 & 0.67 & 0.62 & 0.61 & 0.6 \\
\hline Nisan & 0.62 & 0.65 & 0.59 & 0.78 & 0.61 & 0.64 \\
\hline Mayıs & 0.67 & 0.62 & 0.66 & 0.69 & 0.67 & 0.6 \\
\hline Haziran & 0.59 & 0.54 & 0.67 & 0.7 & 0.70 & 0.6 \\
\hline Temmuz & 0.78 & 0.74 & 0.79 & 0.73 & 0.76 & 0.67 \\
\hline Ağustos & 0.63 & 1.44 & 0.81 & 1.62 & 0.73 & 1.35 \\
\hline
\end{tabular}

Tablo 2. Günlük ortalama meteorolojik değerler ile günlük polen miktarları arasındaki Spearman korelasyon analizi.

\begin{tabular}{cccccc}
\hline & \multicolumn{5}{c}{ Spearman Korelasyon Analizi } \\
\hline & & $\begin{array}{c}\text { Ort. } \\
\text { Sicaklık }\end{array}$ & $\begin{array}{c}\text { Ort. } \\
\text { Nem }\end{array}$ & $\begin{array}{c}\text { Toplam } \\
\text { Yağış }\end{array}$ & $\begin{array}{c}\text { Ort. } \\
\text { Rüzgar } \\
\text { Hızı }\end{array}$ \\
\hline Aydın & 2014 &, 093 &, 006 &, 259 &,- 047 \\
& 2015 &, $413^{*}$ &,$- 388^{*}$ &,- 059 &, 285 \\
Manisa & 2014 &,- 051 &, 003 &, 139 &,- 336 \\
& 2015 &, 167 &,$- 564^{* *}$ &,- 317 &,- 048 \\
Muğla & 2014 &, 480 &,- 561 &,- 450 &,- 143 \\
& 2015 &, $449 *$ &,$- 475^{*}$ &,$- 470^{*}$ &, 368 \\
\hline
\end{tabular}

**. Korelasyon 0.01 düzeyinde anlamlıdır.

*. Korelasyon 0.05 düzeyinde anlamlıdır.

Yıllık zeytin üretiminde klimatik koşullarla beraber $O$. europaea ağacı üzerindeki periyodisitesinde etkili olduğu bilinmektedir [29]. İki ylllk veriler incelendiğinde özellikle Aydın ve Manisa illerinde toplam O. europaea polen sayısının ikinci çalışma yılında ilk yıla oranla önemli bir düşüş gösterdiği kaydedilmiştir. $\mathrm{Bu}$ azalmada meteorolojik faktörlerdeki değişimlerin yanında bu taksonun gösterdiği periyodisitenin de etkili olabileceği düşünülmüștür.

Havadaki polen miktarının yoğunluğu duyarlılığı olan hastalardaki semptomların derecesini etkilemektedir [11]. Amerikan Astım Alerji Akademisi Ulusal Alerji Birimi tarafından belirlenen $\mathrm{m}^{3}$ havadaki eșik değerlere göre [30] O. europaea polenlerinin Manisa atmosferinde orta ve yüksek derecede risk oluşturduğu gün sayısı ilk yıl 25, ikinci yıl ise 18 gündür. Bu değer Aydın'da ilk yıl 37, ikinci yıl 29, Muğla'da ise ilk yıl 30, ikinci yll 23 gün olarak belirlenmiştir.

Tablo 3. Ege Bölgesi'nin farklı șehirlerinde yapılan aeropalinolojik çalıșmalar.

\begin{tabular}{|c|c|c|c|c|c|c|}
\hline & $\begin{array}{l}\text { Örnekleme } \\
\text { metodu }\end{array}$ & $\begin{array}{c}\text { Polen miktarı } \\
\left(\text { polen } / \mathrm{m}^{3}-\mathrm{cm}^{2}\right)\end{array}$ & $\begin{array}{c}\text { Polen } \\
\text { miktarı } \\
(\%)\end{array}$ & $\begin{array}{l}\text { En yüksek } \\
\text { görüldüğü ay }\end{array}$ & $\begin{array}{l}\text { Baskın taksonlar } \\
\text { içerisindeki sırası }\end{array}$ & Referans \\
\hline Aydın & $\mathrm{V}$ & 8082 & 20.92 & Mayıs & 1 & \\
\hline Manisa & V & 2675 & 15.55 & Mayıs & 3 & \\
\hline Muğla & V & 2542 & 7.16 & Mayıs & 3 & \\
\hline İzmir $(1.60 \mathrm{~m}) *$ & G & 240 & 5.3 & Temmuz & 4 & {$[31]$} \\
\hline İzmir $(20 \mathrm{~m})^{*}$ & G & 276 & 4.4 & Temmuz & 5 & [31] \\
\hline Denizli & V & 1359 & 11.35 & Haziran & 3 & {$[22]$} \\
\hline Afyon* & G & 30 & 0.21 & Mayıs-Haziran & & [32] \\
\hline Kütahya* & G & 141 & 2.29 & Mayıs & 8 & [33] \\
\hline Uşak* & G & 20 & 0,37 & Mayıs & & {$[34]$} \\
\hline Bodrum & $\mathrm{V}$ & 2136 & 9.04 & Mayıs & 4 & [35] \\
\hline Buca $1.60 \mathrm{~m}$ (İzmir)* & G & 86 & 3.4 & Mayıs & 6 & {$[36]$} \\
\hline Buca 20m(İzmir)* & G & 65 & 1.9 & Mayıs & 5 & [36] \\
\hline Çeşme & V & 1614 & 12.51 & Mayıs & 2 & [24] \\
\hline Didim & G & 1610 & 9.19 & Mayıs & 3 & [37] \\
\hline Fethiye & G & 456 & 3.20 & Mayıs & 5 & [38] \\
\hline Köyceğiz & G & 687 & 3.91 & Mayıs & 7 & [39] \\
\hline Kuşadası & G & 4473 & 34.46 & Mayıs & 1 & [23] \\
\hline
\end{tabular}

* Polen miktarları Oleaceae familyası olarak değerlendirilmiştir. 
Çalışmamızda elde ettiğimiz veriler ile Ege Bölgesi'nin farklı şehirlerinde yapılan benzer çalıșmalar Tablo 3' te verilmiștir. Volumetrik ve gravimetrik yöntemlerle yapılan bu çalışmalarda $O$. europaea polen miktarı en yüksek oranda Kuşadası'nda yapılan çalışmada kaydedilmiştir. Bunun ardından Aydın ve Manisa, Ege Bölgesinde yapılan çalışmalarda atmosferinde en yüksek zeytin poleni saptanan iller olmuştur.

Çalışmamızda kaydettiğimiz sonuçlarla benzer şekilde İzmir ve Denizli dışındaki tüm şehirlerde zeytin polenlerinin en fazla rastlandığı ay Mayıs olmuştur. Bununla beraber Kuşadası ve Aydın'da zeytin polenleri kaydedilen tüm polenler içerisinde ilk sırada yer almıştır. Bölgede yapılan diğer çalışmalar ışı̆̆ında özellikle Aydın ve Manisa zeytin polenlerinin yüksek oranda kaydedildiği illerdir.Sonuç olarak iki yıllık çalışma süresince elde ettiğimiz veriler Aydın, Manisa ve Muğla illerinde $O$. europaea polenlerinin atmosferde en fazla polenlerine rastlanan taksonlar içerisinde üst sıralarda yer aldığını göstermiş ve her iki yılda da en yüksek polen sayısı Aydın ilinde kaydedildi. Her üç İl'de de atmosferde görülmeye başlama zamanları meteorolojik faktörlerin etkisiyle değişiklik gösterse de, genellikle Nisan-Ağustos aylarında atmosferde izlendiği ve en yüksek miktarın Mayıs ayında kaydedildiği belirlenmiştir. Meteorolojik veriler ve istatistiksel sonuçlar polen miktarı üzerinde ortalama sıcaklığın pozitif, ortalama nemin ise negatif etkisi olduğunu göstermiş, bölgede gerçekleşen bahar yağışlarında polen miktarının yıkanma etkisinden dolayı kısa süreli azalışlar gösterdiği belirlenmiştir. Tarımsal olarak önemli bir faaliyet olması yanında polenlerinin alerjik etkisinin yüksek olması, bu taksona ait polenlerin atmosferdeki miktarlarını ve polinizasyon dönemlerini duyarlı bireyler açısından önemli kılmaktadır. Elde ettiğimiz veriler bu illerde yaşayan ve bu bölgeleri ziyaret edecek olan duyarlı bireylerin günlük hayatlarını daha verimli bir şekilde planlayarak, yaşam kalitesini yükseltmesi açısından katkılar sağlayacaktır.

\section{Teşekkür}

Bu çalışmayı TBAG-113Z065 nolu proje kapsamında destekleyen TUBiTAK'a teşekkürü borç biliriz.

\section{Kaynakça}

[1] D'Amato, G., Lobefalo, G. 1989. Allergenic pollens in the southern Mediterranean area. Journal of Allergy and Clinical Immunology, 83(1), 116122.

[2] Subiza, J., Jerez, M., Jimenez, J.A., Narganes, M.J., Cabrera, M., Varela, S., Subiza, E. 1995. Allergenic pollen pollinosis in Madrid. Journal of Allergy and Clinical Immunology, 96, 15-23.

[3] Ribeiro, H., Cunha, M., Abreu, I. 2003. Airborne pollen concentration in the region of Braga,
Portugal, and its relationship with meteorological parameters. Aerobiologia, 19, 21-27.

[4] Vázquez, L.M., Galán, C., Domínguez- Vilches, E. 2003. Influence of meteorological parameters on olea pollen concentrations in Córdoba (Southwestern Spain). International Journal of Biometeorology, 48, 83-90.

[5] Pınar, N.M., Sakıyan, N., Inceoglu, O., Kaplan, A. 1999. A One Year Aeropalynological Study at Ankara, Turkey. Aerobiologia, 15, 307-310.

[6] Kaplan, A. 2004. Airborne Pollen Grains in Zonguldak, Turkey, 2001-2002. Acta Botanica Sinica, 46(6), 668-674.

[7] Erkara, I.P., Pehlivan, S., Tokur, S. 2007. Concentrations of airborne pollen grains in Eskisehir City (Turkey). Journal of Applied Biological Sciences, 1(1), 33-42.

[8] Çeter, T., Pinar, N.M., Güney, K., Yildiz, A., Aşçı, B., Smith, M. 2012. A 2-year Aeropalynological Survey of Allergenic Pollen in the Atmosphere of Kastamonu, Turkey. Aerobiologia, 28, 355-366.

[9] Tosunoglu, A., Saatcioglu, G., Bekil, S., Malyer, H., Bicakci, A. 2018. Atmospheric pollen spectrum in Stone City, Mardin; the northern border of Mesopotamia/ SE- Turkey. Environmental Monitoring and Assessment, 190, 635.

[10] Uğuz, U., Güvensen, A., Şengonca Tort, N., Eşiz Dereboylu, A., Baran, P. 2018. Volumetric analysis of airborne pollen grains in the city of Uşak, Turkey. Turkish Journal of Botany, 42, 5772.

[11] Biçakçı, A., Altunoğlu, M.K., Tosunoğlu, A., Çelenk, S., Canitez, Y., Malyer, H., Sapan, N. 2009. Türkiye'de Oleaceae familyasına ait allerjenik Olea (zeytin ağacı) ve Fraxinus (dişbudak ağacı) polenlerinin havadaki dağılımları. Astım Alerji İmmünoloji, 7, 133-146.

[12] Loumou, A., Giourga, C. 2003. Olive groves: "The life and identity of the Mediterranean". Agriculture and Human Values, 20, 87-95.

[13] Seçmen, Ö., Gemici, Y., Görk, G., Bekat, L., Leblebici, E. 1995. Tohumlu Bitkiler Sistematiği. Ege Üniversitesi Basımevi, İzmir, $396 \mathrm{~s}$.

[14] Díaz de la Guardia, C., Alba, F., Trigo, M.M., Galán, C., Ruíz, L., Sabariego, S. 2003. Aerobiological analysis of Olea europaea L. pollen in different localities of southern Spain. Grana, 42, 234-243.

[15] Atamer Balkan, B., Meral, S. 2017. Olive oil industry Dynamics. The 35th International Conference of the System Dynamics Society, 1620 July, Cambridge, MA, USA, 2-26.

[16] Sakar, E., Ünver, H. 2011. Türkiye'de zeytin yetiştiriciliğinin durumu ve ülkemizde yapılan bazı seleksiyon ve adaptasyon çalışmaları. 
Harran Journal of Agricultural and Food Science, 15(2), 19-25.

[17] Galán, C., García-Mozo, H., Vázquez, L., Ruiz, L., Díaz de la Guardia, C., Domínguez Vilches, E. 2008. Modeling olive crop yield in Andalusia, Spain. Agronomy Journal, 100(1), 98104.

[18] Bousquet, J., Cour, P., Guerin, B., Michel, F.B. 1984. Allergy in the Mediterranean area I. Pollen counts and pollinosis of Montpellier. Clinical Allergy, 14, 249-258.

[19] Bousquet, J., Guerin, B., Hewitt, B., Lim, S., Michel, F.B. 1985. Allergy in the Mediterranean area III. Cross reactivity among Oleaceae pollens. Clinical Allergy, 15, 439-448.

[20] Gioulekas, D., Chatzigeorgiou, G., Lykogiannis, S., Papakosta, D., Mpalafoutis, C., Spieksma, F.T.M. 1991. Olea europea 3-year pollen record in the area of Thessaloniki, Greece and its sensitizing significance. Aerobiologia, 7, 57-61.

[21] Saatçioğlu, G., Tosunoğlu, A., Malyer, H., Bıçakçı, A. 2011. Airborne pollen grains of Gemlik (Bursa). Asthma Allergy Immunology, 9, 29-36.

[22] Güvensen, A., Celik, A., Topuz, B., Ozturk, M. 2013. Analysis of airborne pollen grains in Denizli. Turkish Journal of Botany, 37, 74- 84.

[23] Tosunoglu, A., Yenigün, A., Bıcakcl, A., Eliacık, K. 2013. Airborne pollen content of Kuşadası. Turkish Journal of Botany, 37, 297-305.

[24] Uguz, U., Guvensen, A., Sengonca Tort, N. 2017. Annual and intradiurnal variation of dominant airborne pollen and the effects of meteorological factors in Çeşme (Izmir, Turkey). Environmental Monitoring and Assessment, 189(10), 530.

[25] Galán, C., Cariñanos, P., Alcázar, P., DominguezVilches, E. 2007. Spanish Aerobiology Network (REA) Management and Quality Manual: Servicio de Publicaciones Universidad de Córdoba. ISBN 978-84-690-6353-8.

[26] Andersen, T.B. 1991. A model to predict the beginning of the pollen season. Grana, 30, 269275.

[27] Bonofiglio, T., Orlandi, F., Sgromo, C., Romano, B., Fornaciari, M. 2009. Evidences of olive pollination date variations in relation to spring temperature trends. Aerobiologia, 25, 227-237.

[28] Recio, M., Cabezudo, B., Trigo, M.M., Toro, F.J. 1996. Olea europaea pollen in the atmosphere of
Malaga (S. Spain) and its relationship with meteorological parameters. Grana, 35, 308-313.

[29] Engindeniz, S., Yercan, M., Adanacıoğlu, H. 2010. The valuation of olive (Olea europaea L.) orchards: a case study for Turkey. Bulgarian Journal of Agricultural Science, 16, 615-621.

[30] American Academy of Allergy Asthma \& Immunology 2019. Reading the chart. www.aaaai.org/global/nab-pollencounts/reading-the-charts (Erişim tarihi: 14.05.2019).

[31] Güvensen, A., Öztürk, M. 2003. Airborne pollen calendar of Izmir - Turkey. Annals of Agricultural and Environmental Medicine, 10, 37-44.

[32] Bıçakçı, A., Ergün, S., Tatlıdil, S., Malyer, H., Ozyurt, S., Akkaya, A., Sapan, N. 2002. Airborne pollen grains of Afyon, Turkey. Acta Botanica Sinica, 44(11), 1371-1375.

[33] Bıçakcı, A., Benlioglu, O.N., Erdogan, D. 1999. Airborne pollen concentration in Kütahya. Turkish Journal of Botany, 23, 75-81.

[34] Bıcakçı, A., Koc, R.D., Tatlıdil, S., Benlioglu, O.N. 2004. Analysis of airborne pollen fall in Usak, Turkey. Pakistan Journal of Botany, 36(4), 711717.

[35] Tosunoglu, A., Bicakcl, A. 2015. Seasonal and intradiurnal variation of airborne polen concentrations in Bodrum, SW Turkey. Environmental Monitoring and Assessment, 187, 167.

[36] Güvensen, A., Öztürk, M. 2002. Airborne pollen calendar of Buca-İzmir, Turkey. Aerobiologia, $18,229-237$.

[37] Bilişik, A., Yenigün, A., Bıçakçı, A., Eliaçık, K., Canitez, Y., Malyer, H., Sapan, N. 2008. An observation study of airborne pollen fall in Didim (SW Turkey): Years 2004-2005. Aerobiologia, 24, 61-66.

[38] Bilişik, A., Bıçakçı, A., Malyer, H., Sapan, N. 2008. Analysis of airborne pollen spectrum in FethiyeMuğla, Turkey. Fresenius Environmental Bulletin, 17, 640-646.

[39] Tosunoglu, A., Bicakcl, A., Malyer, H., Sapan, N. 2009. Airborne pollen fall in Köyceğiz specially protected area (SW Turkey). Fresenius Environmental Bulletin, 18(10), 1860-1865. 